\title{
Genetic basis of speed of development in Senecio vulgaris L. var. vulgaris, $S$. vulgaris ssp. denticulatus (O.F. Muell.) P.D. Sell, and Senecio vernalis Waldst. \& Kit.
}

\author{
HANS PETER COMES* \& JOACHIM W. KADEREIT \\ Institut für Spezielle Botanik u. Botanischer Garten, Johannes Gutenberg-Universität Mainz, Bentze/weg 9, 55099 \\ Mainz, Germany
}

\begin{abstract}
The genetic basis of differences in speed of development from germination to first bud formation was investigated in Senecio vulgaris var. vulgaris and $S$. vulgaris ssp. denticulatus, and also in $S$. vernalis sampled from Israel and Germany. In the case of $S$. vulgaris, $\mathrm{F}_{2}$ segregation analysis and the recovery of very late and very early lines from extreme $F_{2}$ phenotypes showed that differences can be explained by a single major gene model, whereas segregation data from $\mathrm{F}_{2}$ and backcross progenies in $S$. vernalis are not incompatible with a digenic model of inheritance. Senecio vernalis from Israel and $S$. vulgaris var. vulgaris reached the different developmental stages in a substantially shorter time than did C. European $S$. vernalis and $S$. vulgaris ssp. denticulatus. In both species the increased speed of development was achieved through drastic abbreviation of the rosette stage of development rather than through an acceleration of the entire developmental programme. It is suggested that the genes controlling speed of development in $S$. vulgaris and $S$. vernalis may be homologous to major heterochronic genes identified from mutants of Arabidopsis thaliana (e.g. early flowering [elf1-3]).
\end{abstract}

Keywords: early flowering mutants, genetic basis, life history trait, Senecio vernalis, Senecio vulgaris, speed of development.

\section{Introduction}

Speed of development is an important variable in theories of life history evolution (Sibly \& Antonovics, 1992), as it is generally assumed to affect total lifetime fecundity (Lewontin, 1965; MacArthur \& Wilson, 1967). At the macroevolutionary level, variation in developmental timing in a derivative taxon relative to its progenitor is commonly referred to as heterochrony (Diggle, 1992). A full understanding of such major evolutionary changes requires an understanding of the genetic basis of phenotypic differentiation. A knowledge of the inheritance of speed of development is also of value in testing key assumptions of genetic models of life history variation (Anderson \& King, 1970; Lande, 1982; Charlesworth, 1984, 1990).

Developmental timing in plant species can be objectively determined by the number of days

*Correspondence: School of Biological and Medical Sciences, University of St Andrews, St Andrews, Fife KY16 9TH, U.K. required for development from germination to first flower bud formation, anthesis, and fruiting. Information concerning the genetic control of these flowering characters is rapidly increasing in well-defined experimental mutant systems, particularly Arabidopsis thaliana (L.) Heynh. (Koorneef et al., 1991; Sung et al., 1992; Zagotta et al., 1992; Bernier et al., 1993), and many species of agronomic importance, for example maize (e.g. Freeling et al., 1992; see also Bernier, 1988 for a review). In addition, other cereals with genomes suitably mapped at the molecular level have recently been shown to provide excellent material for RFLP marker studies of major genes controlling flowering time and developmental rate (Triticum aestivum, Law et al., 1993; Hordeum vulgare, Laurie et al., 1994). In contrast, the genetics of developmental timing in most wild plant taxa is poorly known (Murfet, 1977; Bernier, 1988). Moreover, only very few studies of natural plant populations have provided evidence of the type and direction of evolutionary change in developmental timing by merging qualitative or quantitative genetic 
information with hypotheses of progenitor-derivative relationships (Stephanomeria, Gottlieb, 1973, 1982; Mimulus, Macnair \& Cumbes, 1989; Fenster \& Ritland, 1994; Fenster et al., 1995). A general conclusion gained from the studies cited above is that there is wide variation in the genetics of developmental timing, and consequently there is no single type of genetic system - either Mendelian inheritance involving only a few genes with major effects, or polygenic inheritance - that underlies the phenotypic differences.

In this paper we examine the genetic basis of intraspecific differences in speed of development from germination to first reproduction in two closely related species of Senecio L. (Compositae), $S$. vulgaris L. and $S$. vernalis Waldst. \& Kit. Substantial differences were analysed between $S$. vulgaris var. vulgaris and $S$. vulgaris ssp. denticulatus (O.F. Muell.) P. D. Sell on the one hand, and between populations of $S$. vernalis from Israel and Germany on the other hand. An almost twofold difference in speed of development has been observed in the former case (Kadereit, 1984a, and unpublished results; Comes, 1995a), and a difference of almost identical magnitude was reported more recently in material of $S$. vernalis from different geographical regions (Comes, 1995b).

The genetic basis of the large difference in speed of development in both $S$. vulgaris and $S$. vernalis is the subject of the present analysis. In the case of the former taxon, it is conceivable that its polyploid genomic constitution may lead to difficulties in interpreting patterns of segregation. However, there is well-documented evidence in $S$. vulgaris of both disomic inheritance at the ray floret locus (Trow, 1912) and fixed heterozygosity at a number of isozyme loci (AAT-3, aEST-1, PGI-2; Ashton \& Abbott, 1992), thus justifying the assumption that the species contains a diploidized genome.

\section{Material and methods}

\section{Senecio vulgaris}

Senecio vulgaris (common groundsel, $2 n=4 \mathrm{x}=40$ ) consists of three taxonomic units, namely ssp. vulgaris var. vulgaris, ssp. vulgaris var. hibernicus Syme, and ssp. denticulatus. Subspecies vulgaris var. vulgaris and ssp. denticulatus were the two taxa of $S$. vulgaris investigated in the present study.

Var. vulgaris is considered to be native to $\mathrm{W}$. Eurasia (Kadereit, 1984b), but is now distributed more or less worldwide, mainly as a ruderal and agricultural weed. In contrast, ssp. denticulatus is a rare taxon from the coasts of W. Europe and the mountains of S. Spain and Sicily (Kadereit, 1984a, and unpublished results), where it occurs in both natural and disturbed habitats (Comes, 1995a; Kadereit, unpublished results). Morphologically, var. vulgaris and ssp. denticulatus are normally distinguished by the presence of ray florets in the latter. Presence vs. absence of ray florets is governed by alternative alleles at a single locus (Trow, 1912). The two taxa differ dramatically in two life history characters, with var. vulgaris normally exhibiting no pronounced seed dormancy and up to twice the speed of development of ssp. denticulatus (Kadereit, 1984a; Comes, 1995a). The difference in seed dormancy appears to be regulated by a single gene with two alleles in ssp. denticulatus from Jersey (Kadereit, 1984a). Presence of seed dormancy was recessive to the absence of seed dormancy in British var. vulgaris. Seed dormancy, however, has also been shown to occur in var. vulgaris from the Mediterranean, where the winter-rain climate does not permit the formation of more than one generation per year (Ren \& Abbott, 1991; Comes, 1995b). Seed dormancy here appears to be regulated digenically (Comes, 1995b).

On the basis of morphological/phenological, geographical and ecological considerations it has been argued that ssp. denticulatus should be regarded as the progenitor of the weedy var. vulgaris, or as close to such (Kadereit, 1984b). On the assumption that the differentiation of var. vulgaris coincided with its geographical/ecological separation from ssp. denticulatus, var. vulgaris may have arisen in late glacial or early postglacial times. At that time ssp. denticulatus, which was probably distributed in Mediterranean coastal habitats during the glacial period, reacted to climatic changes by retreating into higher altitudes in the Mediterranean area, and north along the coasts, i.e. into those areas where it can be found today. At that time many new habitats would have become available for var. vulgaris.

\section{Senecio vernalis}

Senecio vernalis (spring groundsel, $2 n=2 \mathrm{x}=20$ ) is widely distributed in C. to E. Europe, S. W. Asia, Siberia, S. Russia, and Afghanistan (Alexander, 1979). The expansion of its range into $C$. Europe in the last 200 years has been well documented (Hegi, 1987). In C. Europe $S$. vernalis mostly behaves as a winter annual and is polymorphic for seed dormancy, which is regulated by a recessive allele of a single gene (Comes, 1995b). In contrast, material 
from the E. Mediterranean appears to be fixed for seed dormancy, and develops substantially faster from germination to first reproduction (Comes, 1995b).

Although there is no doubt that the C. European populations of $S$. vernalis are of introduced status, it is not known whether this material is directly derived from populations in the E. Mediterranean. It seems likely, however, that E. Mediterranean populations of $S$. vernalis lie within the range the species occupied before man started to alter the 'natural' distribution of the species. In this respect, therefore, C. European populations may be considered as derived, relative to E. Mediterranean populations. Truly native populations of $S$. vernalis in E. Europe may ecologically be very similar to the introduced C. European material.

\section{Crosses}

Crosses were made between $S$. vulgaris var. vulgaris (v) and $S$. vulgaris ssp. denticulatus (d) using material from the Botanic Garden, Heidelberg University (Germany), and from Jersey (Channel Islands; dunes, Les Quennevais, N. of La Pulente, F. Le Sueur, May, 1986), respectively. One individual of $v$ was used as the female parent, and two individuals of $d$ as male parents. One plant each from the two $F_{1}$ families obtained was used for the production by self-pollination of two $\mathrm{F}_{2}$ families, $\mathrm{A}$ and $\mathrm{B}$.

Because $S$. vulgaris has small capitula (width $<6 \mathrm{~mm}$ ) and is extremely self-fertile, all $F_{1}$ hybrids were produced using Alexander's (1979) emasculation technique, and were verified by the presence of short, stubby ray florets, i.e. they were heterozygous for parental, alternative alleles at the ray floret locus (Trow, 1912). The degree of residual selfing on emasculated plants in the absence of cross pollen was low. Of a total of $160 v \times d \mathrm{~F}_{1}$ plants raised in this study only six ( 3.8 per cent) proved to be rayless, apparently resulting from accidental selffertilization of the female parent $(v)$.

Between July and October 1990, the parental taxa $(N=93$ and 129 for ssp. denticulatus and var. vulgaris, respectively), the $\mathrm{F}_{1}$ hybrids $(N=151)$, and the two $\mathrm{F}_{2}$ families $(N=128$ and 220 for $\mathrm{A}$ and $\mathrm{B}$, respectively) were cultivated in a single experiment in order to reduce the environmental variance. Plants were grown in $10 \mathrm{~cm}$ plastic pots under outdoor conditions using six randomized blocks. Two-way analysis of variance (ANOVA) comparison revealed that the two $\mathrm{F}_{2}$ families were not significantly $(P<0.01)$ different from each other, so their data were pooled. This analysis also revealed that neither block (i.e. local environmental) factors nor family $\times$ block effects (i.e. gene-environment interactions) were significant (data not shown). The material was scored daily for the number of days from (1) germination to bud formation, (2) germination to first anthesis, and (3) germination to first fruiting.

To investigate the underlying genetic model further, a simple one-generation divergent selection experiment was carried out. Nine individuals from the $F_{2}$ were selected for extreme low and high phenotypic values for the traits under study. Selected plants were selfed and used for the production of the same number of $\mathrm{F}_{3}$ families of, on average, 26 individuals (range 8--40). Between April and August 1991, the $\mathrm{F}_{3} \mathrm{~S}$ were raised in a fully randomized outdoor bed together with selfed progeny of two unselected individuals of each parental stock (16-36 plants per family).

In a second experiment, 10 plants of each parental taxon were grown in a fully randomized design under a natural light regime in an unheated greenhouse and scored for both stem height and number of leaves at first bud formation, first anthesis, and first fruiting.

Crosses were also made between $S$. vernalis from C. Europe $(c)$ and from Israel $(i) . F_{1}$ progeny was produced by two reciprocal crosses between material collected as rosettes west of Grenzhof/Eppelheim near Heidelberg (topographic map 1: 25000, No. 6517, Mannheim-Südost, RZ 3469.70, HZ 5476.25), and material grown from seed collected in Israel (Jerusalem; ruderal, near Sederot Levi Eshkol/ Nablus Road, H. P. Comes, 12 April, 1990). Further $\mathrm{F}_{1}$ families were raised at the same time (i.e. $\mathrm{F}_{1} \mathrm{~A}$ : $\left.c \times i ; \mathrm{F}_{1} \mathrm{~B}, \quad \mathrm{~F}_{1} \mathrm{C}: i \times c\right)$. These $\mathrm{F}_{1}$ individuals were cross-pollinated at random, and used as male parents for the production of each of two separate families of $\mathrm{F}_{2}$, and backcross progenies $\left(\mathrm{BC}_{1}: c \times \mathrm{F}_{1}\right.$; $\left.\mathrm{BC}_{2}: i \times \mathrm{F}_{1}\right)$, respectively. As most material of $S$. vernalis is self-incompatible, no emasculation of female parents was necessary; however, before crosspollination, pollen of the female parents was washed off the capitula. Between April and August 1992, the parental taxa $(N=64$ and 73 for $S$. vernalis from $C$. Europe and Israel, respectively), their $\mathrm{F}_{1} \mathrm{~s}(N=65)$ and $\mathrm{F}_{2} \mathrm{~S}(N=65)$, and the backcross to the C. European parent $(N=116)$ were cultivated in $8 \mathrm{~cm}$ plastic pots in a completely randomized outdoor bed. No $\mathrm{BC}_{2}$ seed germinated. The material was scored as described above for the two $S$. vulgaris experiments. Within the $F_{1}, F_{2}$, and $B_{1}$ progenies, no significant differences between families (of either 
reciprocal or nonreciprocal types) were observed and their data were pooled in all subsequent analyses.

\section{Statistical procedures}

The relatively large $F_{2}$ and $\mathrm{BC}_{1}$ segregation populations produced for $S$. vulgaris and $S$. vernalis, respectively, were examined for evidence of separation into normally distributed series differing in developmental timing. To superimpose normal curves onto each putative series we adopted a simplified maximum likelihood solution of truncated normal distributions (Cohen, 1959). The expected frequencies were computed from the estimated mean and standard deviation, summed over series, and compared with observed frequencies of the entire distribution by chi-square analysis with $n-6$ d.f., where $n$ is the number of pairwise comparisons (Bliss, 1967; pp. 162-167). Truncation points and transformations were chosen so as to produce reasonably normal distributions and to maximize the agreement between observed and expected frequencies. Fitted curves were then used to predict the number of plants belonging to each series, and the estimates, in turn, were subjected to Mendelian analyses in order to test the adequacy of a simple genetic model.

\section{Results}

Not unexpectedly, the phenological traits (time to bud formation, first anthesis, and first fruiting) had very similar frequency distributions and significantly high positive phenotypic correlations with each other in all parental generations and their progeny (e.g. for $S$. vulgaris $\mathrm{F}_{2} \mathrm{~B}: r=0.94-0.98, N \geq 203$; for $S$. vernalis $\left.\mathrm{BC}_{1}: r=0.91-0.96, N \geq 105\right)$. Accordingly, one of these traits was considered accurate enough to be used as an indicator of general developmental timing, and only the recordings for time to bud formation, as the environmentally least affected trait (Comes, unpublished results), are presented here.

\section{Senecio vulgaris}

The number of days for development from germination to bud formation for the parental taxa, the $F_{1}$, and the pooled $F_{2}$ families is shown in Fig. 1. Subspecies denticulatus was substantially more variable than var. vulgaris $(\mathrm{CV}=0.21,0.11$, respectively). This difference in variance could be removed or substantially lowered by $\arcsin (1 /(x+1))$ or free (Smith, 1976) transformations. Accordingly, the difference in variance is likely to represent a scale effect.

The frequency distribution of the $F_{2}$ shows a separation of 'early' and 'late' developing plants in a bimodal fashion, but there is also an undefined zone of overlap. In a normal probability plot of the overall distribution the section below 40 days proved to be satisfactorily linear. On the assumption that these plants were all early developing, a normal curve truncated at 40 days was fitted onto the lower part of the histogram and extrapolated into the zone of overlap of both putative $\mathrm{F}_{2}$ types. Truncated distributions were then iteratively fitted to the right side of the antimode (41-42 days), thereby accounting for the portion of overlapping plants from the early developing subgroup. Because the late developing series was obviously right-tailed, both the arcsin of the data was taken and three probable outliers (* in Fig. 1), identified by exploratory data analysis (MiniTAB, 1991), were rejected to improve normality. The best fit between expected frequencies, summed over both series, and observed frequencies resulted in placing an upper truncation point at 43 days $\left(\chi_{34}^{2}=30.23,0.7>P>0.6\right)$. Figure 1 shows that the expected frequencies for the 'early' and 'late' series (smooth lines) are very close to the observed $F_{2}$ data. It is important to note that locating upper boundaries at 44 or 45 days, and no other change, gave a similarly good agreement to the above result, but including the outliers resulted either in a less satisfactory fit $\left(\chi_{45}^{2}=47.88,46.48\right.$, $0.5>P>0.1$, for 43 and 44 days, respectively) or even in a significant discrepancy $\left(\chi_{45}^{2}=65.57\right.$, $P<0.05$, for 45 days).

According to our best fit, the total sample of 345 observed $\mathrm{F}_{2}$ plants (without outliers) can be subsumed in two normal curves, one including an expected number of 267 early, and the other an expected number of 80 late developing plants. Thus taken over both fitted curves (early and late) only two more plants were expected than were observed. The early/late ratio found is not significantly different from a Mendelian 3:1 ratio $\left(\chi_{1}^{2}=0.70\right.$, $0.5>P>0.4)$ and is best explained by postulating a single gene with a dominant allele for expression of early development present in var. vulgaris and a recessive allele for late development at the locus in ssp. denticulatus. Similarly to the $\mathrm{F}_{1}$, however, the mean of the early developing $F_{2}$ series is shifted towards higher values than those of var. vulgaris (Fig. 1), indicating an incomplete rather than a strictly dominant pattern of inheritance of early/late development. The gene postulated is likely to regulate general developmental timing, owing to the 

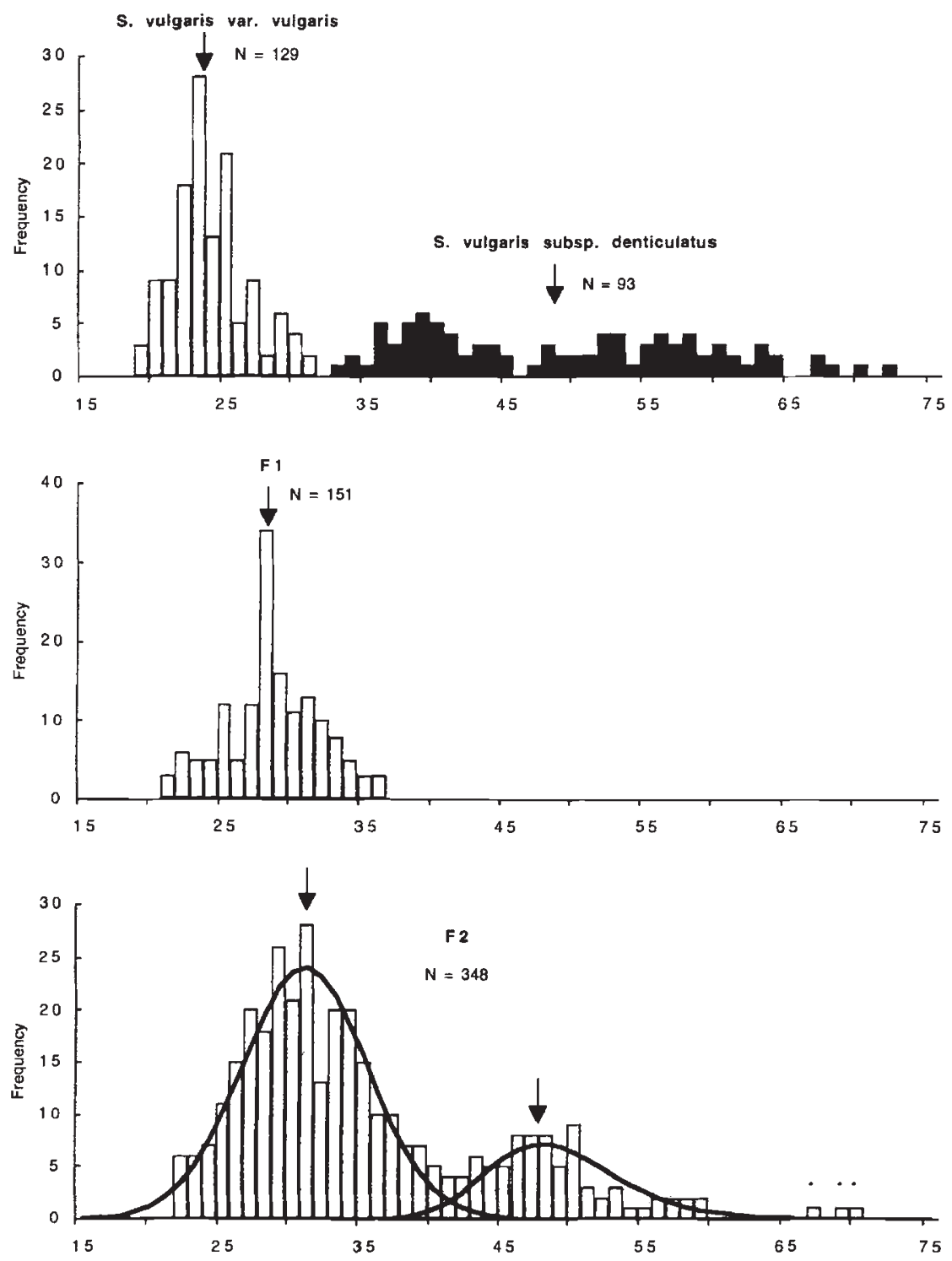

DAYS FROM GERMINATION TO BUD FORMATION
Fig. 1 Observed frequencies for the time to bud formation in Senecio vulgaris ssp. denticulatus, S. vulgaris var. vulgaris, and their $\mathrm{F}_{1}$ and $\mathrm{F}_{2}$ generations. Smooth lines indicate expected $\mathrm{F}_{2}$ frequencies according to two truncated normal distributions with days and $\arcsin (1 /($ days +1$))$ as the metameter for the 'early' and 'late' $F_{2}$ series, respectively. Means are designated by arrows. Note that three probable outliers $(*)$ were omitted from the analysis. extremely high phenotypic correlations of time to bud formation with time to first anthesis and first fruiting (see above).

The one-generation selection experiment offers additional evidence for a simple genetic basis of speed of development in $S$. vulgaris. Figure 2 shows the means of the nine $F_{3}$ families for time to bud formation plotted against the value of their selected $\mathrm{F}_{2}$ parent; the control values of ssp. denticulatus and var. vulgaris are also represented. The regression between the $F_{2}$ parent and the $F_{3}$ offspring values, shown in Fig. 2, has a slope of $0.687( \pm 0.044)$ whereas the entire data set has a slope of 0.567
$( \pm 0.080)$. The strong $F_{2}-F_{3}$ regression clearly reflects genetic segregation between six $F_{2}$ parents with 'early' and three parents with 'late' development. An estimate of narrow-sense heritability $\left(h^{2}\right)$, calculated from the $F_{2}-F_{3}$ slope and adjusted for inbreeding (Smith \& Kinman, 1965), equalled 0.46, thus indicating a high heritability (additive genetic variance) of developmental timing. More importantly, however, after a single generation of selfing, all $\mathrm{F}_{3}$ families derived from extreme $\mathrm{F}_{2}$ individuals came near the control values of the parental taxa (Fig. 2 and Table 1). This is expected if there are only a single or few loci involved. Furthermore, a 
Fig. 2 Regression of mean phenotypic values of time to bud formation for nine $F_{3}$ families (E1-6, L1-3) against the $F_{2}$ parent plant value. $F_{2}$ parents were selected for extreme phenotypic values from an $F_{2}$ of 348 plants. The slope of the best fitted line equals $0.687( \pm 0.044)$, corresponding to an adjusted heritability estimate of 0.46 . Parental control values of Senecio vulgaris ssp. denticulatus (dent) and $S$. vulgaris var. vulgaris (vulg) are also presented, but were not included in the regression analysis.

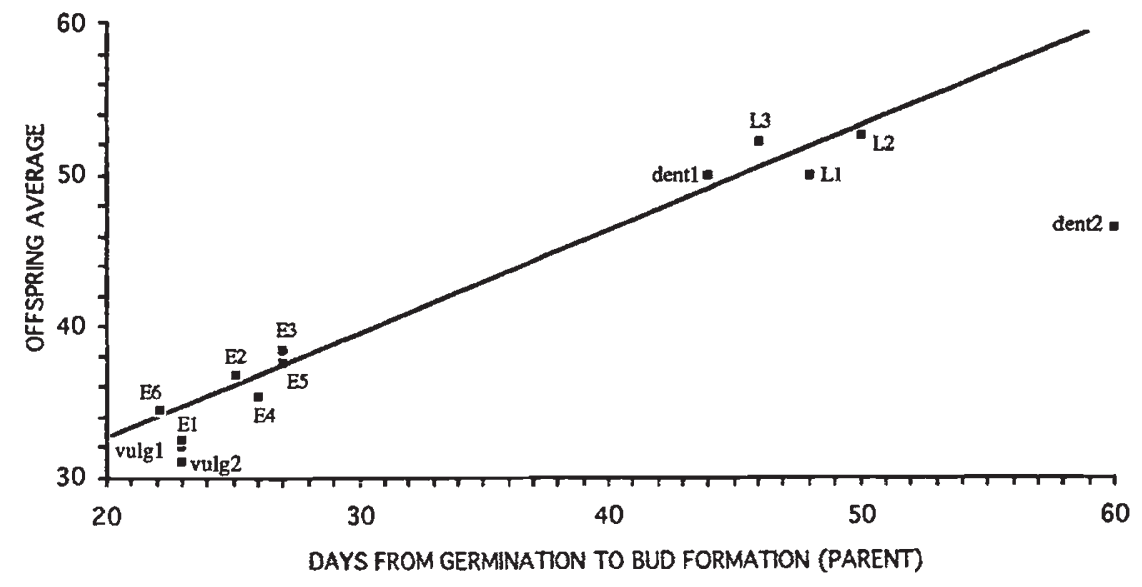

Table 1 Parent values, means and SE of time to bud formation for nine $\mathrm{F}_{3}$ families and controls of Senecio vulgaris ssp. denticulatus (dent) and $S$. vulgaris var. vulgaris (vulg)

\begin{tabular}{lcccr}
\hline Family & Parent value & Mean & SE & $N$ \\
\hline vulg1 & 23 & 31.8 & 0.54 & 21 \\
vulg2 & 23 & 31.0 & 0.55 & 16 \\
E1 & 23 & 32.6 & 0.74 & 23 \\
E2 & 25 & 36.6 & 1.13 & 14 \\
E3 & 27 & 38.9 & 0.52 & 40 \\
E4 & 26 & 35.8 & 0.52 & 37 \\
E5 & 27 & 37.6 & 0.43 & 29 \\
E6 & 22 & 34.6 & 0.69 & 29 \\
L1 & 48 & 50.3 & 1.86 & 8 \\
L2 & 50 & 52.7 & 0.84 & 20 \\
L3 & 46 & 52.5 & 0.69 & 28 \\
dent 1 & 44 & 49.9 & 0.76 & 26 \\
dent2 & 60 & 47.1 & 0.92 & 36 \\
& & & &
\end{tabular}

E, $L$ designate $F_{3}$ families selected for early and late development, respectively. $N$ indicates the number of individuals analysed per family.

regression slope within the cluster of the 'late' $F_{3}$ families alone (L1-3) was not significantly different from zero $\left(b=0.050 \pm 0.644, r^{2}(\operatorname{adj})=0.0, t_{1}=0.08\right.$, $P=0.95)$, so there was no residual heritability left for speed of development $\left(h^{2}=0.033\right)$. This result is entirely consistent with the hypothesis that the respective 'late' $F_{2}$ parents were homozygous recessive for the postulated gene controlling speed of development. In contrast, a significant regression slope within the cluster of 'early' $\mathrm{F}_{3} \mathrm{~s}(\mathrm{E} 1-6)$ indicated that there was still a heritable component in the degree of developmental timing shown by 'early' $\mathrm{F}_{2}$ parents $\left(b=0.900 \pm 0.283, \quad r^{2} \quad(\operatorname{adj})=0.65\right.$, $\left.t_{4}=3.18, \quad P<0.05 ; h^{2}=0.60\right)$. On the assumption that these latter plants were homozygous dominant at the major locus, this observation may suggest that additional minor genes (modifiers) affecting developmental timing were present as well. The failure to detect residual heritability among the 'late' $\mathrm{F}_{3}$ s could depend on the small number of families raised.

A distinct difference in growth pattern was found between early flowering var. vulgaris and late flowering ssp. denticulatus (Fig. 3). It was obvious that whereas the latter undergoes a distinct rosette stage consisting of a large number of leaves, followed by moderate internode elongation of the axis after bud formation, height increment is greatly enhanced after bud formation in var. vulgaris, which is a sparsely leaved plant with less close spacing of the basal nodes. Figure 3 also illustrates that rates of leaf production do not differ between progenitor and derivative, indicating that early flowering in var. vulgaris does not arise as a simple consequence of its faster growth, but instead is achieved by the abbreviation of the rosette stage of development.

\section{Senecio vernalis}

The number of days for development from germination to bud formation for the parental taxa and the $\mathrm{F}_{1}, \mathrm{~F}_{2}$, and $\mathrm{BC}_{1}$ progenies is shown in Fig. 4. The results are similar to those found in $S$. vulgaris, with the late flowering plants of $S$. vernalis from C. Europe being much more variable for the character observed than the early flowering plants from Israel $(\mathrm{CV}=0.20,0.12$, respectively). The same explanation as given above also applies here.

The frequency distribution of the $\mathrm{BC}_{1}$ appears to fall broadly into two groups, namely those individuals that are predominantly like the $F_{1}$, and those that show a developmental timing as in $S$. vernalis 


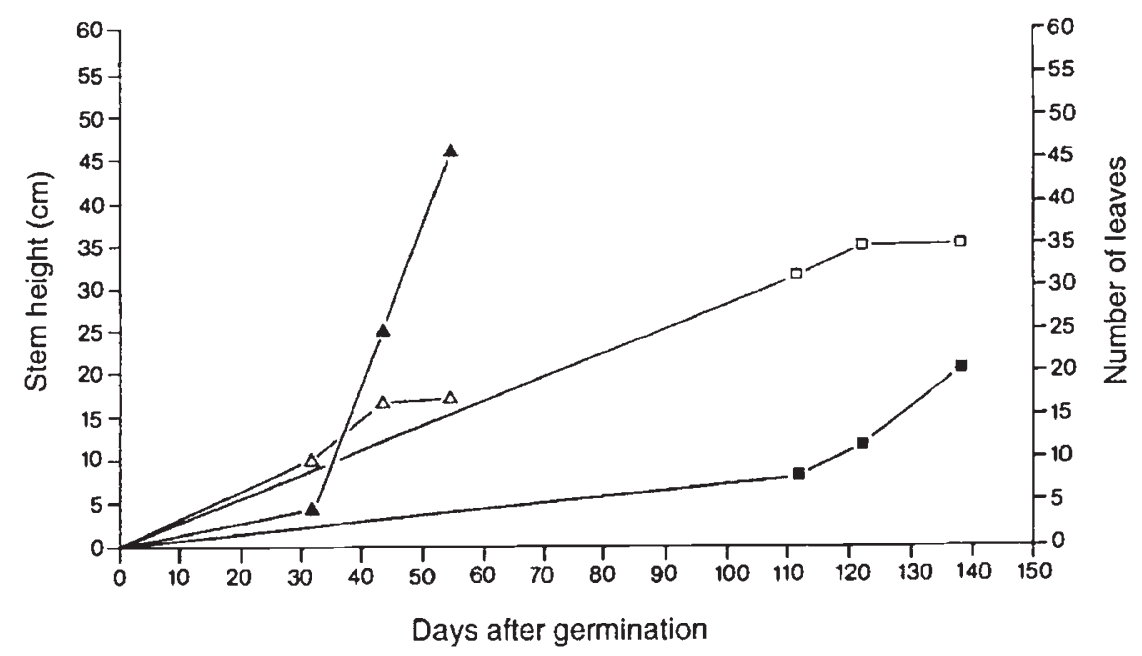

Fig. 3 Increment of both stem height (solid symbols) and number of leaves (open symbols) in Senecio vulgaris ssp. denticulatus (squares) and S. vulgaris var. vulgaris (triangles) following germination. Measurements were made at the time of first budding, first anthesis, and first fruiting. The data presented are based on the mean value of 10 plants of each taxon. from C. Europe. However, following a similar calculation and transformation pattern as was carried out for the $\mathrm{F}_{2}$ in $S$. vulgaris, the overall distribution of the $\mathrm{BC}_{1}$ did not easily fit into two normal distributions truncated at any reasonable point on each side of the zone of overlap between the two hypothesized classes. Figure 4 presents two typical normal distributions found, one for the 'early' individuals truncated at 52 days, and the other for the 'late' individuals truncated at 66 days, fitted to the overall distribution of the $116 \mathrm{BC}_{1}$ plants. Despite the fact that the observed distribution appears far from two normal distributions, there is formal agreement when one probable outlier (* in Fig. 4 ) is excluded $\left(\chi_{77}^{2}=90.78,0.25>P>0.1\right)$. Hence, the $\mathrm{BC}_{1}$ seemed to segregate into two subpopulations, with an estimated number of 81 'early' and 37 'late' individuals, and with three plants expected but not observed. These data, in fact, are not inconsistent with a 3:1 ratio expected for two independent loci acting dominantly $\left(\gamma_{1}^{2}=2.54,0.2>P>0.1\right)$. With such a model, the allelic constitution of the Israeli and $C$. European parental material could be denoted as $A A B B$ and $a a b b$, respectively, and the $\mathrm{BC}_{1}$ would then consist of four genotype classes ( $A a B b, A a b b, a a B b$ and $a a b b$ ) with identical 'early' phenotypes for the first three. Because the means of both the $F_{1}$ and the early developing $\mathrm{BC}_{1}$ series are shifted towards higher values in comparison to that of $S$. vernalis from Israel (Fig. 4), early development appears to be only incompletely dominant over late development, thus paralleling the situation found in $S$. vulgaris.

Because of the generally low significances in the data presented above, this model may not be taken as an exact representation of the genetics underlying speed of development in $S$. vernalis, and therefore should be re-evaluated with subsequent derived generations to test the predicted digenic genotype of individual $\mathrm{BC}_{1}$ plants. Nevertheless, the model does show that the $\mathrm{F}_{1}$ and the 'early' $\mathrm{BC}_{1}$ series should resemble one another closely (see above). It also predicts the scarcity of 'late' genotypes observed in the $\mathrm{F}_{2}$ as such genotypes would segregate at a rate of only $1 / 16$. However, if the behaviour of the two hypothesized $\mathrm{BC}_{1}$ distributions is taken to discriminate 'early' and 'late' classes of the present $F_{2}$ data set, any confident classification of comparatively 'late' $\mathrm{F}_{2}$ individuals is prevented because their phenotypic values lie within the small range of overlap between the two $\mathrm{BC}_{1}$ distributions (Fig. 4).

There is a large discrepancy for growth pattern between 'early' $S$. vernalis from Israel and 'late' $S$. vernalis from Germany (Fig. 5). Stem elongation, though rapid after bud formation in both accessions, is initiated from a large and densely leafy rosette in German material, but follows a nonrosette stage of growth in Israeli material. As already described above for $S$. vulgaris, developmental rates in terms of leaf production are virtually identical in the two $S$. vernalis accessions, thus indicating that early flowering of the Israeli material is achieved through a drastic abbreviation of the rosette stage of development rather than through an acceleration of the entire developmental programme.

\section{Discussion}

Attempts to understand and explore the evolution of life history characters (Sibly \& Antonovics, 1992) have utilized both single-locus or two-locus (Ander- 
Fig. 4 Observed frequencies for the time to bud formation in Senecio vernalis from Germany, $S$. vernalis from Israel, and their $\mathrm{F}_{1}, \mathrm{BC}_{1}\left(\mathrm{~F}_{1} \times S\right.$. vernalis, Germany) and $\mathrm{F}_{2}$ generations. Smooth lines indicate expected $\mathrm{BC}_{1}$ frequencies according to two truncated normal distributions with days and $\arcsin (1 /($ days +1$))$ as the metameter for the 'early' and 'late' $\mathrm{BC}_{1}$ series, respectively. Means are designated by arrows. Note that one probable outlier $\left.{ }^{*}\right)$ was omitted from the analysis.
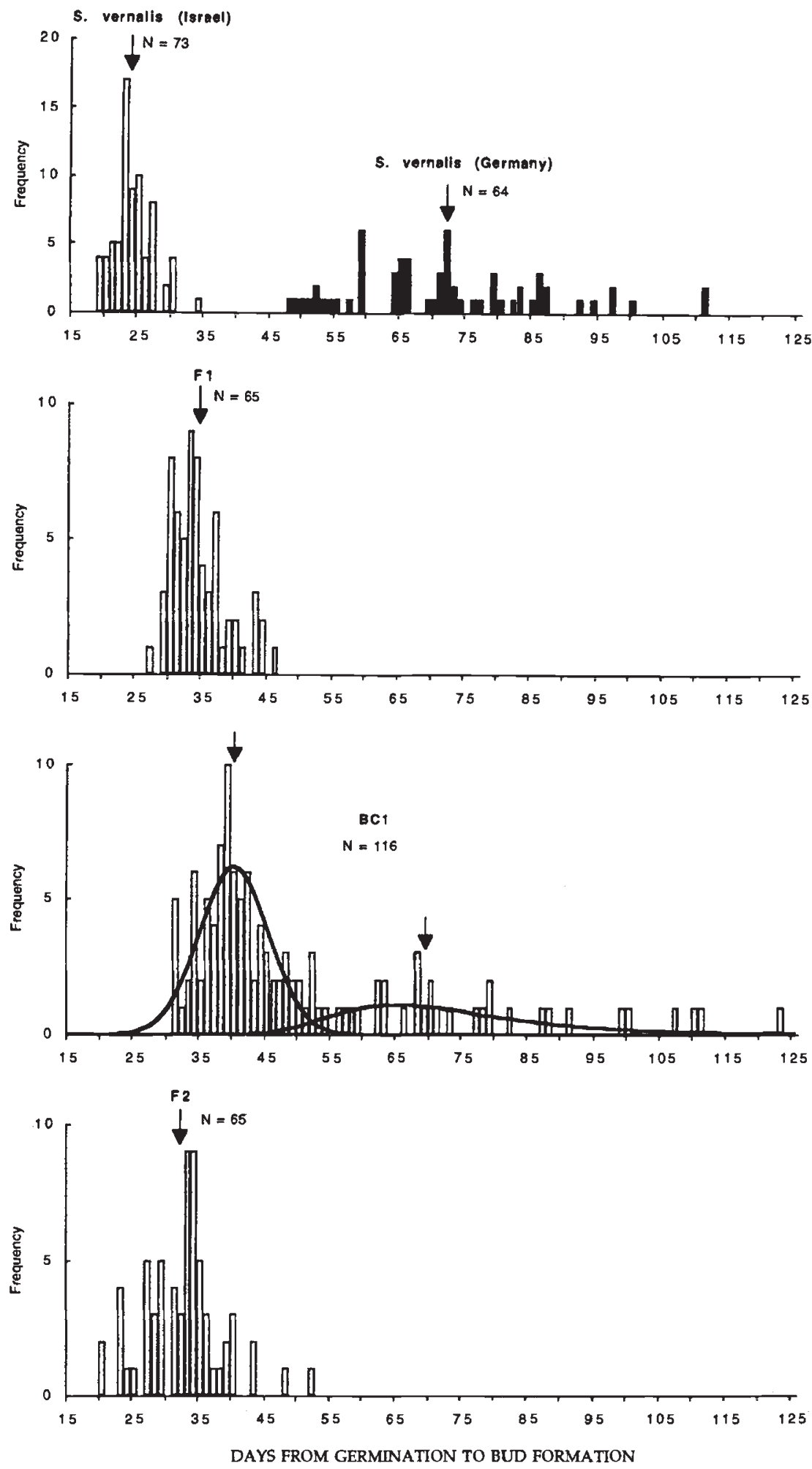


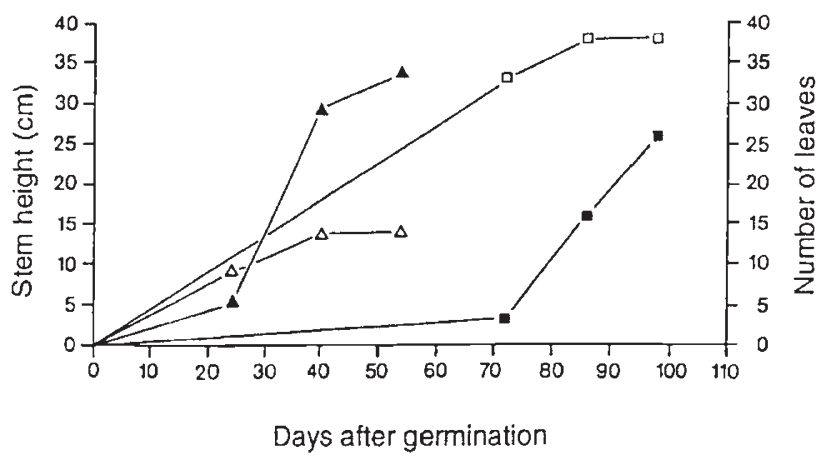

Fig. 5 Increment of both stem height (solid symbols) and number of leaves (open symbols) in Senecio vernalis from Germany (squares) and Israel (triangles) following germination. Measurements were made at the time of first budding, first anthesis, and first fruiting. The data presented are based on the mean value of 60 and 69 plants from Germany and Israel, respectively.

son \& King, 1970) and quantitative (e.g. Lande, 1982) genetic models. Quantitative genetic models have been used more commonly because (1) life history characters, based on their usually continuous variation, have been assumed or shown to be inherited polygenically (Lande, 1982; Charlesworth, 1984, 1990; Stearns, 1992); and (2) when the nature and number of genes underlying the observed phenotype are unknown, a quantitative genetic approach has been considered useful for some defined purpose (Smith, 1991).

The present study has shown that the life history character 'speed of development' (i.e. time from germination until first bud formation, anthesis, and fruiting) in two closely related Senecio species, $S$. vulgaris and $S$. vernalis, is inherited by genes with large effects. However, whereas an almost twofold difference in this character between $S$. vulgaris var. vulgaris and ssp. denticulatus is largely governed by one major gene, a difference of almost identical magnitude appears to be inherited digenically in $S$. vernalis from Israel and Germany.

In combination with the absence or presence of seed dormancy, which has been shown previously to be inherited monogenically in both species (Kadereit, 1984a; Comes, 1995b), the dramatic difference in speed of development between var. vulgaris and ssp. denticulatus within $S$. vulgaris results in very divergent life histories. Whereas var. vulgaris typically occurs in ruderal habitats and can produce up to three more or less synchronized and successive generations per year, at least in the mild climate of S.W. Germany (Vack, 1992), ssp. denticulatus is a winter annual of coastal W. and N.W. European and mountainous S. European habitats. In $S$. vernalis, fast genotypes with seed dormancy from Israel and slow genotypes without seed dormancy from C. Europe can be regarded as being well adapted to their respective climates. These are a strict and reasonably reliable winter-rain climate in Israel and a mild subatlantic climate without severe frosts in S.W. Germany.

If, in $S$. vulgaris, the fast-developing ruderal var. vulgaris is accepted as being derived from the slowdeveloping ssp. denticulatus then var. vulgaris may be regarded as being fixed for an 'early flowering' mutant allele relative to ssp. denticulatus, which is fixed for a 'late flowering' allele. In $S$. vernalis, however, the direction of evolutionary change is more ambiguous between slow-developing material from $\mathrm{C}$. Europe and fast-developing material from Israel. Nevertheless, by abbreviating the rosette stage of development, and showing a marked reduction in leaf number, the early phenotypes of $S$. vulgaris and $S$. vernalis resemble three "early flowering' mutants (elf $1-3$ ) recently described from Arabidopsis thaliana by Zagotta et al. (1992). Elf 1-3 are stage transition and probably loss-of-function mutations, which is in accordance with their recessive mode of inheritance (see below). It might be conceivable that the major gene regulating speed of development in $S$. vulgaris and one of the two genes that act similarly in $S$. vernalis are homologous to one of the elf genes of $A$. thaliana.

It is noteworthy that a rosette stage is involved in virtually all cases where major genes which dramatically influence speed of development have been identified (annual vs. biennial races in Melilotus alba Med. [Clarke, 1935], Beta vulgaris L. [Abegg, 1936], Hyoscyamus niger L. [Sinnott, 1960]; annual Lactuca graminifolia Michx. vs. biennial L. canadensis L. [Whitaker, 1944]; length of rosette growth duration in Carthamus flavescens Spreng. and $C$. tinctorius L. [Imrie \& Knowles, 1970]). Accordingly, all of these examples of natural species are candidates for the action of genes like elf $1-3$. However, in contrast to the action of elf mutant alleles in $A$. thaliana (Zagotta et al., 1992) the 'early flowering' alleles of $S$. vulgaris var. vulgaris and $S$. vernalis are dominant in expression. Bernier et al. (1993) recently concluded that most 'late flowering' mutant alleles (not explicitly stage transition mutations) are recessive, but Freeling et al. (1992) observed that most heterochronic mutants that retard developmental stage transitions are dominant. The two taxa investigated here would fit the conclusion by Bernier et al. (1993) when the alleles of ssp. denticulatus and C. European $S$. vernalis are interpreted as 'late flow-

(c) The Genetical Society of Great Britain, Heredity, 77, 544-554. 
ering' mutant alleles, instead of interpreting their alternative alleles as 'early flowering' mutations as suggested by the phylogenetic relationships at least in S. vulgaris. Thus the dominance relationships of the $S$. vulgaris/S. vernalis 'early flowering' alleles are incompatible with all former evidence when interpreted as 'early flowering' stage transition mutations. In contrast to the examples summarized by Freeling et al. (1992) and Bernier et al. (1993), however, the cases discussed here do not represent mutant systems of young age, but rather natural taxa which have had ample time to undergo evolutionary transition of dominance relationships.

Though aiming at a testable hypothesis, our suggestion that the major genes controlling speed of development in $S$. vulgaris and $S$. vernalis are homologous to major heterochronic elf $1-3$ genes in $A$. thaliana needs to be treated with caution. Even if allelic differences in gene action (i.e. dominance/ recessiveness) may be neglected in this connection, the possibility of genetic heterogeneity cannot be ruled out. Thus, the early developing Senecio types could have mutations in non-elf genes conferring early development or, vice versa, there might be other Arabidopsis mutations of a similar phenotype. The examination of phenotypes, however, will not help to confirm or refute the action of one of the elf loci in $S$. vulgaris and $S$. vernalis. In order to do that, it will be necessary to examine the gene itself.

\section{Acknowledgements}

We gratefully acknowledge valuable comments of Drs R. J. Abbott and M. G. Ritchie (St Andrews University, Scotland) and very helpful corrections of two anonymous referees on earlier drafts of this manuscript. We also wish to thank $\mathrm{Dr}$ Z. R. Sung (University of California, Berkeley) for kindly drawing attention to a valuable reference, Miss A. Berg for preparing Figs 2 and 5, and Miss P. Siegert who assisted in growing the $S$. vulgaris plants for developmental analysis. This research was conducted while H. P. C. was a recipient of an LGFG doctoral grant from the Land Baden-Württemberg, Germany.

\section{References}

ABEGG, F. A. 1936. A genetic factor for the annual habit in beets and linkage relationships. J. Agric. Res., 53, 493-511.

ALEXANDER, J. C. M. 1979. The Mediterranean species of Senecio sections Senecio and Delphinifolius. Notes $R$.

Bot. Gard. Edinburgh, 37, 387-428.

ANDERSON, w. W. AND KING, C. E. 1970. Age-specific selec- tion. Proc. Natl. Acad. Sci. U.S.A., 66, 780-786.

ASHTON, P. A. AND ABBOTT, R. J. 1992. Isozyme evidence and the origin of Senecio vulgaris (Compositae). Pl. Syst. Evol., 179, 167-174.

BERNIER, G. 1988. The control of floral evocation and morphogenesis. Ann. Rev. Pl. Physiol. Pl. Mol. Biol., 39, $175-219$.

Bernier, G., havelange, A., houssa, C., Petitjean, A. AND LEJEUNE, P. 1993. Physiological signals that induce flowering. Pl. Cell, 5, 1147-1155.

BLıss, C. 1. 1967. Statistics in Biology, vol. 1. McGraw-Hill, New York.

CHARLESWORTH, в. 1984. The evolutionary genetics of life histories. In: Shorrocks, B. (ed.) Evolutionary Ecology, pp. 117-133. Blackwell Scientific Publications, Oxford.

CHARLESWORTH, B. 1990. Optimization models, quantitative genetics and mutation. Evolution, 44, 520-538.

CLARKE, A. E. 1935. Inheritance of annual habit and mode of pollination in an annual white sweet clover. J. Am. Soc. Agric., 27, 492-496.

COHEN, A. C., JR. 1959. Simplified estimators for the normal distribution when samples are singly censored or truncated. Technometrics, 1, 217-237.

COMES, H. P. 1995a. Senecio vulgaris L. ssp. denticulatus (O.F. Muell.) P.D. Sell and S. vulgaris ssp. vulgaris var. vulgaris on Jersey (Channel Islands). Watsonia, 20, 205-227.

COMES, H. P. 1995b. Genecological and isozyme studies in Senecio vernalis Waldst. \& Kit. and $S$. vulgaris L. var. vulgaris (Asteraceae) from Central Europe and Israel. Flora, 190, 1-24.

DIGGLE, P. K. 1992. Development and the evolution of plant reproductive characters. In: Wyatt, R. (ed.) Ecology and Evolution of Plant Reproduction, pp. 326-355. Chapman and Hall, New York, London.

FENSTER, C. B., DIGGLE, P. K., BARRETT, S. C. H. AND RITLAND, K. 1995. The genetics of floral development differentiating two species of Mimulus (Scrophulariaceae). Heredity, 74, 258-266.

FENSTER, C. B. AND RITLAND, K. 1994. Quantitative genetics of mating system divergence in the yellow monkeyflower species complex. Heredity, 73, 422-435.

FREELING, M., BERTRAND-GARCIA, R. AND SINHA, N. 1992. Maize mutants and variants altering developmental time and their heterochronic interactions. BioEssays, 14, 227-236.

GOTTLIEB, L. D. 1973. Genetic differentiation, sympatric speciation and the origin of a diploid species of Stephanomeria. Am. J. Bot., 60, 545-553.

GotTLieB, L. D. 1982. Does speciation facilitate the evolution of adaptation? In: Barigozzi, C. (ed.) Mechanisms of Speciation, pp. 176-190. Alan R. Liss, New York.

HEGI, G. 1987. Illustrierte Flora von Mitteleuropa, Ed. 2, Bd. VI/4. Verlag Paul Parey, Berlin.

IMRIE, B. C. AND KNOWLES, P. F. 1970. Inheritance studies in interspecific hybrids between Carthamus flavescens and C. tinctorius. Crop Sci., 10, 349-352.

Kadereit, J. w. 1984a. Studies on the biology of Senecio vulgaris L. ssp. denticulatus (O.F. Muell.) P.D. Sell. New 
P.555.561 are civarlable in the Missing Pages collection (SLC) Alio availuble online.

554 H. P. COMES \& J. W. KADEREIT

Phytol., 97, 681-689.

KADEREIT, J. W. 1984b. The origin of Senecio vulgaris (Asteraceae). Pl. Syst. Evol., 145, 135-153.

KOORNEEF, M., HANHART, C. J. AND VAN DER VEEN, J. H. 1991. A genetic and physiological analysis of late flowering mutants in Arabidopsis thaliana. Mol. Gen. Genet., 229, 57-66.

LANDE, R. 1982. A quantitative genetic theory of life history evolution. Ecology, 63, 607-615.

LAURIE, D. A., PRATCHETT, N., BEZANT, J. H. AND SNAPE, J. w. 1994. Genetic analysis of a photoperiod response gene on the short arm of chromosome $2(2 \mathrm{H})$ of Hordeum vulgare (barley). Heredity, 72, 619-627.

LAW, C. N., DEAN, C. AND COUPLAND, G. 1993. Genes controlling flowering and strategies for their isolation and characterization. In: Jordan, B. R. (ed.) The Molecular Biology of Flowering, pp. 47-68. CAB International, Oxford.

LEWONTIN, R. C. 1965. Selection for colonizing ability. In: Baker, H. G. and Stebbins, G. L. (eds) The Genetics of Colonizing Species, pp. 77-91. Academic Press, New York.

MACARTHUR, R. H. AND WILSON, E. O. 1967. The Theory of Island Biogeography. Princeton University Press, Princeton, NJ.

MACNAIR, M. R. AND CUMBES, O. J. 1989. The genetic architecture of interspecific variation in Mimulus. Genetics, 122, 211-222.

minitab. 1991. miNitab Reference Manual. Release 8. Data Tech Industries, Valley Forge, PA.

MURFET, 1. C. 1977. Environmental interaction and the genetics of flowering. Ann. Rev. Pl. Physiol., 28, 253-278.

REN, Z. AND ABBOtT, R. J. 1991. Seed dormancy in Medi- terranean Senecio vulgaris L. New Phytol., 117, 673-678. SIBLY, R. AND ANTONOVICS, J. 1992. Life-history evolution. In: Berry, R. J., Crawford, T. J. and Hewitt, G. M. (eds) Genes in Ecology, pp. 87-122. Blackwell Scientific Publications, Oxford.

SINNotT, E. w. 1960. Plant Morphogenesis. McGraw-Hill, New York.

SMITH, J. D. AND KINMAN, M. L. 1965. The use of parentoffspring regression as an estimator of heritability. Crop Sci., 5, 595-596.

SMlTH, J. E. K. 1976. Data transformation in analysis of variance. J. Verb. Lear. Verb. Behav., 15, 339-346.

SMiTH, R. E. 1991. Genetic and phenotypic aspects of lifehistory evolution in animals. Adv. Ecol. Res., 21, 63-120.

StEarns, s. c. 1992. The Evolution of Life Histories. Oxford University Press, Oxford, New York, Tokyo.

SUNG, Z. R., BELACHEW, A., SHUNONG, B. AND BERTRANDGARCIA, R. 1992. EMF, an Arabidopsis gene required for vegetative shoot development. Science, 258, 1645-1650.

TROW, A. H. 1912. On the inheritance of certain characters in the Common Groundsel - Senecio vulgaris Linn. and its segregates. J. Genet., 2, 239-276.

vack, A. 1992. Demographische und Experimentelle Untersuchungen Saisonaler Variation am Beispiel von Senecio vulgaris L. var. vulgaris - Genetische Differenzierung oder Modifikatorische Plastizität? Ph.D. Dissertation, Universität Heidelberg.

WHITAKER, T. H. 1944. The inheritance of certain characters in a cross of two American species of Lactuca. Bull. Torrey Bot. Club, 71, 347-355.

ZAGOTTA, M. T., SHANNON, S., JACOBS, C. AND MEEKSWAGNER, D. R. 1992. Early-flowering mutants of Arabidopsis thaliana. Aust. J. Pl. Physiol., 19, 411-418. 